\title{
A (DES)CRIMINALIZAÇÃO DO ABORTO: UMA QUESTÃO DE SAÚDE PÚBLICA'
}

\section{THE (DES)CRIMINALIZATION OF ABORTION: A PUBLIC HEALTH ISSUE}

\author{
Laís Dockorn Nunes Pereira² Giovana Knorst Chaves ${ }^{3}$ \\ Janaína Machado Sturza ${ }^{4}$
}

DOI: https://doi.org/10.37767/2591-3476(2020)11

\section{RESUMEN:}

El aborto es una práctica que se perpetúa a través del tiempo, siendo tratada de maneras diferentes y específicas en cada momento histórico. Hoy en día, en Brasil y la mayor parte de América Latina, el aborto ilegal e inseguro sigue siendo un grave problema de salud pública, porque aun siendo ilegal, se practica y su solución es un reto que permea el requisito de medidas urgentes en el proceso de despenalización. El objetivo general de esta investigación es describir la relación entre el aborto y la salud pública en Brasil, (des) penalización la perspectiva de la influencia de los derechos humanos, destacando la salud de las mujeres, la falta de planificación familiar y las consecuencias. Esta investigación se caracteriza como estudio bibliográfico, tomando como método de enfoque la investigación deductiva, a través de la doctrinaria, documental y el uso de datos y herramientas disponible en Internet..

\section{ABSTRACT \\ Abortion is a practice that is perpetuated through time, being treated in different and specific ways in each historical moment. Today, in Brazil and in most of Latin America, illegal and unsafe abortion is still a serious public health problem, because even being illegal, it is practiced and its solution is a challenge that permepasses the requirement of urgente measures in the process of descrimination. The general objective of this research is to describe the relationship between abortion and public health in Brazil, from the perpective of (dis) criminalization, from the influence of human rights, highlighting women's health, lack of family planning and its consequences. This research is characterized as a bibliographical study, having as a method}

\footnotetext{
1 Artigo elaborado a partir do projeto de pesquisa "A complexa efetivação do direito à atenção básica em saúde no Brasil: paradoxos teóricos e normativos", apoiado pelo PIBIC/CNPq, a ser desenvolvido no período de agosto de 2018 à julho de 2021, junto ao Programa de Pós Graduação em Direito - Mestrado e Doutorado em Direitos Humanos da Unijui/RS.

2 Graduanda em Direito pela UNIJUI. Bolsista PIBIC/CNPq do projeto "A complexa efetivação do direito à atenção básica em saúde no Brasil: paradoxos teóricos e normativos". E-mail: laisdockorn@gmail.com; ORCID iD: https://orcid.org/0000-0001-8653-3024.

3 Graduanda em Direito pela UNIJUÍ. Bolsista PIBIC/CNPq do projeto "A complexa efetivação do direito à atenção básica em saúde no Brasil: paradoxos teóricos e normativos". Integrante do grupo de pesquisa Biopolítica e Direitos Humanos. E-mail: giovanaknorst@gmail.com. ORCID iD: https://orcid. org/0000-0001-9619-1275.

4 Pós doutora em Direito pelo Programa de Pós-Graduação em Direito da Universidade do Vale do Rio dos Sinos - UNISINOS. Doutora em Direito pela Escola Internacional de Doutorado em Direito e Economia Tullio Ascarelli, da Universidade de Roma Tre/Itália. Mestre em Direito pela Universidade de Santa Cruz do Sul - UNISC. Especialista em Demandas Sociais e Políticas Públicas também pela UNISC. Graduada em Direito pela UNISC. Professora na Universidade Regional do Noroeste do Estado do Rio Grande do Sul - UNIJUÍ, lecionando na graduação em Direito e no Programa de Pós-Graduação em Direito - Mestrado e Doutorado. Integrante do Grupo de Pesquisa Biopolítica e Direitos Humanos (CNPq). E-mail: janasturza@hotmail.com; ORCID iD: http://orcid.org/0000-001-9290-1380.
} 
of approach the deductive, through doctrinarian research, documentation and the use of data and search tools made available on the Internet.

PALABRAS CLAVE: Derechos humanos; Planificación familiar; Salud de la mujer.

KEY WORDS: Human rights; Family planning; Woman's health

\section{Introdução}

O aborto é uma prática que se perpetua através do tempo, sendo tratado de formas diferentes e específicas em cada momento histórico. Razão de diversos conflitos e posicionamentos, tal ato envolve, além de aspectos culturais, aspectos éticos, morais, religiosos, médicos e jurídicos. Ao longo de muitos anos, a gravidez foi considerada como algo sagrado. Inclusive, em vários momentos históricos, as mulheres eram endeusadas por terem o "poder" de gerar uma nova vida. No entanto, muitas não desejavam manter sua gestação e recorriam a abortos, em sua maioria clandestinos, em situações precárias, provocando graves sequelas a sua saúde física e psicológica. No Brasil, podese perceber que ao longo da história, o conteúdo relativo ao aborto, seja em momentos de ditadura ou de democracia, sempre foi regido por uma sociedade patriarcal.

Assim, essa pesquisa tem como objeto geral descrever a relação entre o aborto e a saúde pública no Brasil, sob a perspectiva da (des) criminalização a partir dos direitos humanos, destacando os aspectos históricos do aborto no Brasil, a saúde da mulher, a carência de planejamento familiar e suas consequências, visto que diante de tantas outras normativas que caracterizam marcos para a proteção de mulheres vulneráveis em situação de aborto, ainda não foram atingidos idealmente. Percebe-se, assim, um estático desenvolvimento do aborto no país, uma vez que não há avanços, mas também não há retrocessos.

\section{Resultados e discussões}

\section{Conceito de aborto}

Segundo o $\mathrm{AbcMed}^{5}$, o aborto é a interrupção precoce da gravidez, resultando na morte do concepto ou sendo causada por ela. Já para o site Politize! ${ }^{6}$, o aborto é a interrupção de uma gravidez antes que ela se complete, ou seja, a expulsão do embrião ou do feto antes que ele se desenvolva totalmente, isso de um ponto de vista médico.

Conforme o Ministério da Saúde, o aborto é a interᄀrupção da gravidez até a $20^{\mathrm{a}}$ ou $22^{\mathrm{a}}$ semana, com o produto da concepção pesando menos de $500 \mathrm{~g}$, sendo este eliminado no processo de abortamento. De acordo com o dicionário jurídico DireitoNet ${ }^{7}$, o aborto consiste na interrupção da gravidez com a consequente morte do produto da concepção, que pode ser realizada pela própria gestante ou terceira pessoa.

\footnotetext{
5 Site AbcMed, artigo aborto: O que é? Como é feito? Quais são os riscos? Como age a (pílula do dia seguinte)? 14 jun, 2013. Disponível em: < https://www. abc.med.br/p/saude-da-mulher/359669/aborto+o+que+e+como+e+feito+quais+sao+os+riscos+como+age+a+quot+pilula+do+dia+seguinte+quot.htm $>$. 6 Site Politize!, artigo aborto: entenda tudo sobre essa questão. 17 nov, 2016. Disponível em: <https://www.politize.com.br/aborto-entenda-essa-questao/>. 7 Dicionário jurídico online, conceito de aborto. 18 ago, 2009. Disponível em: $<$ https://www.direitonet.com.br/dicionario/exibir/2/Aborto >.
} 
Nesse sentido, nota-se que o a palavra aborto, apesar das poucas letras, traz muito impacto, sendo sempre necessitado o seu conceito acompanhado. Por fim, constatase que aborto vem do latim "ab-ortus", e transmite a idéia de privação do nascimento, interrupção voluntária da gravidez, com a morte do produto da concepção.

\section{Aspectos históricos do aborto no Brasil}

É de suma importância que se comente a respeito dos aspectos históricos do aborto no Brasil, principalmente nas décadas de 1964 a 1985, como também em 1985 até os dias de hoje. Seja no duro período da ditadura, ou no período democrático, o aborto sempre existiu, e, apesar das evoluções mundo afora, infelizmente o mesmo foi e continua sendo um grande tabu em meio a sociedade brasileira, assim como em grande parte da América Latina.

De 1964 a 1979, não existia, praticamente, nenhum debate público a respeito do aborto. Apesar das poucas falas, o Executivo chegou a decretar um novo Código Penal, em 1969, que não entrou em vigor, mantinha a incriminação do aborto, com exceção dos dois permissivos do código anterior, mas alterava as punições, introduzia controles do Estado para o aborto permitido por lei e aumentava a pena para a mulher que provocasse 0 auto-aborto (ROCHA, 2006, p. 370). Igualmente, no âmbito da sociedade civil, a discussão também era restrita, pois não existiam correntes que se manifestassem publicamente. Nem mesmo as feministas discutiam sobre o assunto, muito se vale pelo fato da época, pois aqui se relata os acontecimentos no auge da ditadura.

Entre 1979 e 1985, novas mudanças de pensamento ocorreram no campo político. No entanto, nada foi relacionado diretamente ao aborto. Nesse sentido, o Ministério da Saúde, em 1983, formulou um programa, chamado Programa de Assistência Integral à Saúde da Mulher (Paism). Nele, era possível perceber algumas breves referências acerca da questão, encontradas no diagnóstico apresentado sobre a saúde da população feminina no país, em que se constatava a falta de informações a respeito do tema. (ROCHA, 2006, p. 370). Naquela época, as informações focavam as formas de prevenção da gravidez indesejada, para que não fossem realizados abortamentos, além do foco no planejamento familiar, métodos contraceptivos e controle de natalidade do país.

A partir de 1985 até 1989, o Brasil passava por uma transição democrática, abandonando o governo autoritário e dando boas-vindas à democracia. Nesse período, houve melhorias de instituições por meio da Assembleia Nacional Constituinte, que passaram a considerar um pouco mais a questão do aborto em meio as discussões sociais.

Entre 1985 e 1989, a sociedade civil passou a aparecer e a atuar em face do Estado. Os direitos das mulheres entraram na agenda política dos poderes Executivo e Legislativo e novos direitos foram assegurados na Constituição de 1988. (ROCHA, 2006, p. 371). A partir daí, a discussão sobre o aborto tomou novas proporções, essencialmente no tocante do embate entre o movimento feminista e as entidades religiosas. Com o fim da ditadura militar, em 1985, as mulheres ampliaram sua luta para ocupar espaços políticos na esfera do Executivo, exercendo um papel fundamental na Assembleia Nacional Constituinte, em relação aos movimentos de mulheres e seus direitos. Vale ressaltar que, nesse cenário, foi criado o Conselho Nacional dos Direitos da Mulher (CNDM). (ROCHA, 2006, p. 371). 
Em 1989 se inicia uma nova fase na configuração do Estado e da sociedade. A Constituição Cidadã abriu horizontes para transformações a serem realizadas pelos três poderes (Legislativo, Executivo e Judiciário). A democracia acabou por trazer algumas significativas mudanças na feição das discussões e decisões sobre os direitos das mulheres e, nesse quadro, sobre a questão do aborto. (ROCHA, 2006, p. 372). O que se sabe é que, durante o tempo mencionado, o aborto ganhou mais visibilidade, passou a ser discutido e conhecido pela sociedade. Porém, quanto à legislação, as mudanças não se deram na mesma intensidade, exceto pelo fato de que conseguiu-se estabelecer normas técnicas e criar serviços que procuram garantir o acesso ao aborto previsto em lei e o atendimento das mulheres em situação de abortamento. (ROCHA, 2006, p. 374). Nota-se que o que impede as mudanças legais são as tendências opostas ao aborto que tencionam o Parlamento para que nada seja feito. Não há avanços, mas o lado positivo é que também não há retrocessos.

Com a democracia, a sociedade civil conquistou voz, mesmo que muitos direitos não foram ainda totalmente conquistados. Mas se o avanço, mesmo que pequeno, for levado em conta, o povo caminha na busca de seus direitos e todo passo mesmo que curto, já é um motivo de vitória. Afinal, o Brasil é uma sociedade essencialmente patriarcal e, para que tal padrão seja superado, são necessários cada vez mais debates acerca desta problemática.

\section{Uma questão de saúde pública}

Nos dias atuais, no Brasil e na maior parte da América Latina, o aborto clandestino e inseguro é ainda um grave problema de saúde pública, e sua solução é um desafio que perpassa a exigência de medidas urgentes no processo de descriminalização. (DOMINGOS e MERIGHI, 2010, p. 178). Para Pimenta e Vilella $(2012$, p. 2)

A dignidade humana e os direitos fundamentais da mulher, considerando-se que a vida do feto, em geral, deve ser protegida e reconhecendo que a educação na área da sexualidade e da reprodução é comprovadamente a única política pública que apresenta resultados satisfatórios na redução da incidência do aborto, conclui-se que qualquer legislação que vise a diminuir a realização de abortamentos, deve ser preventiva e não punitiva.

Dessa maneira, evidencia-se que a prinıcipal problemática referente ao aborto fundamenta-se em uma questão de saúde pública, bem como a sua forma de realização, que na maioria dos casos ocorre de forma clandestina e sem segurança, já que mesmo sendo ilegal, ele é praticado. Destarte, o ato de abortar de forma insegura pode ser considerado uma injustiça social e fere os direitos humanos.

Segundo o IAG, Instituto Alan Guttmacher ${ }^{8}$, entidade americana que estuda a questão do aborto no mundo, cerca de 1 milhão de mulheres abortam todos os anos no Brasil. Mas a questão principal é: quantas mulheres morrem por ano por causa de abortos feitos em locais clandestinos e quantas ficam com sequelas para o resto da vida por abortos maus feitos?

8 VARELLA, Mariana. Artigo aborto: um problema de saúde pública. Site UOL, página Doutor Dráuzio Varella Disponível em: $<$ https://drauziovarella.uol. com.br/para-as-mulheres/aborto-um-problema-de-saude-publica/>. Acesso em: 22 abr. 2019. 
Segundo a Organização Mundial da Saúde (OMS), a proibição do aborto não é eficaz para combater sua prática. Muito pelo contrário, leis restritivas estão associadas com altas taxas de abortos inseguros, que consequentemente levam a morte ou a complicações físicas e psicológicas irreversíveis. Portanto, deve-se lembrar que a mulher merece uma vida digna e saudável e que a criminalização do aborto não contribui para que isso seja de fato garantido.

Para melhor entender os fatos é preciso da análise de alguns números em relação ao aborto no Brasil. Conforme a Pesquisa Nacional de Aborto 2016, realizada através de um levantamento domiciliar que combina técnica de urna e entrevistas face-a-face com mulheres de 18 a 39 anos, evidencia-se que o aborto é um fenômeno frequente e persistente entre as mulheres de todas as classes sociais, grupos raciais, níveis educacionais e religiões: na faixa etária de 35 a 39 anos, aproximadamente 18\% das mulheres já abortou. Entre as de 38 e 39 anos a taxa sobe a quase 19\%. No entanto, nota-se que há uma frequência maior do último aborto entre as mulheres jovens, com $29 \%$ dos abortos ocorrendo em idades que vão de 12 a 19 anos, 28\% dos 20 aos 24 anos, caindo para abaixo a partir dos 25 anos. (DINIZ, MEDEIROS, MADEIRO, 2016, p. 655).

No ponto de vista econômico e social, vivemos em um país extremamente desigual, e essa disparidade é vista significativamente quando analisamos o aborto no Brasil. Mulheres de classes mais altas conseguem abortar, pelo menos, com o mínimo de higiene e segurança, no ponto de vista médico. Porém, quando o aborto é feito em mulheres pobres, o quadro é outro. Como essas mulheres não tem condições financeiras, acabam abortando em qualquer lugar, sendo expostas e sujeitas a todo tipo de agressão, seja física ou psicológica. Além disso, segundo Domingos e Merighi (2010, p. 178)

A clandestinidade transforma o aborto em um negócio lucrativo, garantindo a impunidade para aqueles que o realizam. Quem tem maior poder aquisitivo utiliza as clínicas especializadas e têm acesso a uma assistência qualificada, enquanto quem não tem condições financeiras busca pessoas não habilitadas e métodos abortivos rudimentares [...].

Segundo o Ministério da Saúde (2009, p. 16), "as mulheres organizadas reivindicaram, portanto, sua condição de sujeitos de direito, com necessidades que extrapolam o momento da gestação e parto, demandando ações que lhes proporcionassem a melhoria das condições de saúde em todas os ciclos de vida". Ao contrário, percebe-se que a prática do aborto se constitui como forma discriminação e violência contra as mulheres em vários serviços de saúde. Segundo Santos (2013, p. 499), a precariedade e demora na assistência, pouco interesse dos médicos e das equipes em escutar e orientar as mulheres, além da discriminação verbal, são comportamentos identificados em vários profissionais e clínicas de saúde.

Ademais, gastos com a saúde de mulheres que fizeram abortos maus sucedidos são muito elevados. Segundo o ginecologista Jefferson Drezett ${ }^{9}$, coordenador do Ambulatório de Violência Sexual e de Aborto Legal do Hospital Pérola Byington, em São Paulo, "os recursos que gastamos para tratar graves complicações do aborto clandestino

9 VARELLA, Mariana. Op cit. Disponível em: <https://drauziovarella.uol.com.br/para-as-mulheres/aborto-um-problema-de-saude-publica/>. Acesso em: 22 abr. 2019. 
são muito maiores que os recursos de que precisaríamos para atender as mulheres dentro de um ambiente seguro e minimamente ético e humanizado". Outrossim, Santos (2013, p. 495) afirma que:

\begin{abstract}
Ações relacionadas à saúde da mulher, como o planejamento familiar, vinculadas à atenção primária, são parte das responsabilidades mínimas da gestão municipal, conforme define a Norma Operacional da Assistência à Saúde do Sistema Único de Saúde (SUS). Entretanto, alguns municípios não têm conseguido implantar e programar estratégias adequadas para o fornecimento de anticoncepcionais à população nem garantir o acompanhamento desses [...]
\end{abstract}

Dessa maneira, o que explica em parte o grande número de abortos provocados no Brasil são as deficiências dos programas oficiais de planejamento familiar, que não educam. (TELAROLLI, 1997, p. 97). Sem a contracepção correta e sem o acompanhamento e o planejamento adequado - apesar deste último estar previsto pela Constituição Federal, em seu artigo 226, parágrafo sétimo e também pela Lei nº 9.263, de 1996 -, muitas mulheres engravidam e abortam em seguida pois não possuem o amparo que necessitam. Assim, as complicações de saúde decorrentes dos abortos, são a primeira causa de mortalidade materna na América Latina, inclusive no Brasil. (TELAROLLI, 1997, p. 98).

\title{
III. Conclusão
}

A defesa em torno da descriminalização do aborto acontece ao redor da questão de tratá-lo como um problema de saúde pública e permitir que a mulher o realize conforme for sua vontade, até certo período da gestação, assim, ocorrendo de forma segura para mulher, sem a colocar em risco e preservando sua saúde psicológica. Com efeito, pode-se constar que a proibição do aborto não possui eficácia para que a prática seja impedida, conforme rege a Organização Mundial da Saúde (OMS), uma vez que, as complicações de saúde decorrentes dos abortos, são a primeira causa de mortalidade materna na América Latina, inclusive no Brasil. Ora, pois, salienta-se que a criminalização intensifica a mortalidade materna e o número de abortos provocados.

Assim, enfrentar o fenômeno do aborto como uma questão de saúde pública significa entendê-lo como uma questão de cuidados em saúde e não como um ato de infração moral de mulheres. Precisamos tirar isso dos paradigmas religiosos e morais e tratá-lo como um problema social, disponibilizando a assistência que for necessária. Por fim, diante da pesquisa realizada, infere-se que os objetivos requeridos foram atingidos, uma vez que, foi possível constatar que as mulheres grávidas, sendo um grupo vulnerável, merecem exercer seus direitos de modo efetivo, cabendo ao Estado propor esta garantia. Assim, o direito à vida vem sendo flexibilizado afim de assegurar direitos, como o direito à liberdade e sexualidade da mulher, já que a inviolabilidade prevista do direito à vida não é absoluta. 


\section{REFERÊNCIAS BIBLIOGRÁFICAS}

- ANJOS, Karla Ferraz dos; SANTOS, Vanessa Cruz; SOUZAS, Raquel; EUGÊNIO, Benedito Gonçalves (2013): Aborto e saúde pública no Brasil: reflexões sob a perspectiva dos direitos humanos. Rio de Janeiro, v. 37, n. 98, pp. 504-515. Disponível em: < http://www. scielo.br/pdf/sdeb/v37n98/a14v37n98.pdf>. Acesso em: 23 abr. 2019.

- BRASIL. Ministério da Saúde (2009): Política nacional de atenção integral à saúde da mulher: princípios e diretrizes. Disponível: <http://bvsms.saude.gov.br/bvs/publicacoes/ politica_nacional_mulher_principios_diretrizes.pdf >. Acesso em: 23 abr. 2019.

- CHADE, Jamil (2017): Proibição não reduziu abortos, constata OMS. Estadão, Suíça. Disponível em: <https://saude.estadao.com.br/noticias/geral,proibir-aborto-nao-reduznumero-de-ocorrencias-diz-oms,70002018731>. Acesso em: 23 abr. 2019.

- DINIZ, Debora. MEDEIROS, Marcelo. MADEIRO, Alberto (2016): Pesquisa Nacional de Aborto 2016. Artigo Especial, pp. 653-660. Disponível em: < http://www.scielo.br/pdf/csc/ v22n2/1413-8123-csc-22-02-0653.pdf.> Acesso em: 22. Abr. 2019.

- DOMINGOS, Selisvane; MERIGHI, Miriam (2010): O aborto como causa de mortalidade materna: um pensar para o cuidado de enfermagem. Rio de Janeiro, pp. 177-181. Disponível em: <http://www.scielo.br/scielo.php?script=sci_arttext\&pid =S1414-81452010000100026>. Acesso em: 22 abr. 2019.

- ROCHA, Maria Isabel Baltar (2006): A discussão política sobre aborto no Brasil: uma síntese. R. bras. Est. Pop, v. 23, n. 2, p. 369-374, São Paulo. Disponível em: <http://www. scielo.br/pdf/rbepop/v23n2/a11v23n2.pdf>. Acesso em: 23 abr. 2019.

- SANDI, Stella de Faro; BRAZ, Marlene (2010): As mulheres brasileiras e o aborto: uma abordagem bioética na saúde pública. Revista Bioética, v. 18, n. 1, pp. 131-153. Disponível em: < http://revistabioetica.cfm.org.br/index.php/revista_bioetica/article/view/541/527>. Acesso em: 23 abr. 2019.

- SANTOS, Vanessa Cruz; ANJOS, Karla Ferraz dos; SOUZA, Raquel; EUGÊNIO, Benedito Gonçalves. (2013): Criminalização do aborto no Brasil e implicações à saúde pública. Revista de Bioética, vol. 21, no. 3, pp. 494-508. Brasília. Disponível em: < http://www. scielo.br/pdf/bioet/v21n3/a14v21n3.pdf>. Acesso em: 21 abr. 2019.

- TELAROLLI, Rodolpho (1997): Mortalidade infantil: uma questão de saúde pública. São Paulo. Editora Moderna.

- VARELLA, Mariana. Artigo aborto: um problema de saúde pública. Site UOL, página Doutor Dráuzio Varella. Disponível em: <https://drauziovarella.uol.com.br/para-asmulheres/aborto-um-problema-de-saude-publica/>. Acesso em: 22 abr. 2019.

- VILLELA, Wilza; PIMENTEL, Silvia (2012): Um pouco da história da luta feminista pela descriminalização do aborto no Brasil. Ciência Cultura. vol. 64. pp. 20-21. Disponível em: <http://cienciaecultura.bvs.br/scielo.php?script=sci_arttext\&pid =S0009-67252012000200010>. Acesso em: 22 abr. 2019. 